\title{
Identifying Concern and Stress of Parents, Students and Teachers With the Social Distance Planning Process and Reopening of Schools During Covid-19 Pandemic: a Qualitative Study
}

\section{Saeed Bashirian}

Hamadan University of Medical Sciences School of Public Health

\section{Majid Barati}

Hamadan University of Medical Sciences School of Public Health

Maryam Afshari ( $\sim$ afshari_m20@yahoo.com )

Hamadan University of Medical Sciences School of Public Health

\section{Seyede Somaye Mirmoini}

Hamadan University of Medical Sciences

Javad Zavar Chahar Tagh

Hamadan University of Medical Sciences

\section{Research article}

Keywords: Concern, Stress, Parents, Students, Teachers, Social Distance Planning, Reopening of Schools, Covid-19

Posted Date: January 23rd, 2021

DOI: https://doi.org/10.21203/rs.3.rs-149322/v1

License: (c) (i) This work is licensed under a Creative Commons Attribution 4.0 International License.

Read Full License 


\section{Abstract}

Background: With the closure of schools as a result of the social distancing plan, the negative emotions that individuals experience became complicated. Therefore, the present study provides deep understanding of the concerns and stresses of parents, students and teachers about the process of social distance planning and reopening of schools during COVID-19 pandemic.

Methods: This qualitative study was conducted in 2020 . The data for this study were collected through semi-structured interviews with teachers, students and their parents in Tuyserkan. Sampling was performed by purposeful sampling method with the maximum variation. Data analysis was performed simultaneously with data collected by content analysis method.

Results: In general, the majority of participants were stressed and concerned about the social distancing plan and the reopening of schools during Covid-19 pandemic. During data analysis, 74 primary codes, 13 sub-themes and 6 themes were obtained. The themes included preparing factors (knowledge), reinforcing factors, preparing factors (attitude), enabling factors, epidemiological aspects of the subject and quality of life.

Conclusions: Identifying and explaining the concerns and stress of parents, students and teachers about the process of social distance planning and reopening of schools during COVID-19 pandemic will help policy makers and administrators for planning and interventions related to this.

\section{Key Points}

- The majority of participants were stressed and concerned about the social distancing plan and the reopening of schools during Covid-19 pandemic.

- During data analysis, 74 primary codes, 13 sub-themes and 6 themes were obtained.

- The themes included preparing factors (knowledge), reinforcing factors, preparing factors (attitude), enabling factors, epidemiological aspects of the subject and quality of life.

- The themes led to the development of PRECEDE-PROCEED model in this study.

\section{Background}

COVID-19 is a threat to health around the world [1] and the largest outbreak of pandemic pneumonia since the outbreak of Severe Acute Respiratory Syndrome (SARS) in 2003, with a total reported higher incidence and mortality than SARS [2]. The outbreak of the disease was first reported in late December 2019 when the symptoms of a disease similar to pneumonia of unknown cause were identified [3]. Since then, the number of patients has been increasing around the world, with the World Health Organization declares COVID-19 a public health and an international concern [4]. 
Since the prevalence of the disease, many attempts have been made to break the transmission chain throughout the world. In China, travel restrictions were imposed in an unprecedented move to control the spread of the virus. During several days, quarantine was added to provinces and cities, affecting a total of more than 50 million individuals. Many individuals stayed at home and isolated themselves socially to prevent infection [5]. Also, in the countries of the world, various plans have been made to break the chain of disease transmission [6], and in Iran, a social distancing plan was implemented including controlling the entry and exit of travelers, closing schools and universities, closing parks, recreation centers, and swimming pools, triple grouping of guilds and jobs for activities, scheduling services in government offices, reducing staff traffic in offices, prohibition of any gathering ceremony, maximum restriction on passenger transportation by plane, trains and buses, health controls at the entrances of cities, and fines for various individuals from the social distancing plan and in cooperation with the Ministry of Health and Education Medicine and other executive organizations [7].

With implementing transmission chain break plans, COVID-19 pandemic causes individuals to fear and worry because the future situation is not clear. Therefore, timely understanding of the mental health status of the community is essential [8]. Previous studies have shown a wide range of psychosocial effects of diseases on the health of individuals during the outbreak of infection. At the individual level, individuals are more likely to experience fear of diseases or death, feelings of helplessness, and stigma $[9,10]$.

With the closure of schools, the negative emotions that individuals experience became complicated [11], especially, one of the cases of social distancing plan for individuals who deal with schools was implemented in the country. The students who are studying at school are a large group of individuals who are involved in this plan in terms of mental health and its subsequent problems. The students' parents also faced several problems following the implementation of this plan and the closure of schools. Currently, no information is available on mental health of the general public, especially teachers, students and their parents due to COVID-19 pandemic. According to the research team, most studies focus on the prevalence, and epidemiological and clinical features of the patients $[12,13]$, the genomic features of the virus (14) and global health challenges [15]. However, there is no study on the psychological effect of COVID-19 on the population of teachers, students and their parents. Therefore, the present study investigated the psychological effect and mental health on the prevalence of COVID-19 in the population of teachers, students and their parents. Therefore, this study was conducted aimed to identify the concerns and stress of parents, students and teachers of schools from the process of social distance planning and reopening of schools during COVID-19 pandemic.

\section{Methods}

\section{Ethical considerations}

This study was approved by the Ethical Committee of the Hamadan University of Medical Sciences (reference number: IR.UMSHA.REC.1399.156). The informed consent form, obtaining of participants after 
informing them of the purpose of the study, rights, potential risks and benefits, procedures to be undertaken, the volunteering of subjects in the study and recording of their voices.

\section{Design}

This qualitative study was done with the purpose of identifying parents', students' and teachers' concerns and stress about the process of social distancing and reopening schools during the Covid-19 outbreak using a content analysis approach. In the present study, semi-structured interviews with parents, students and teachers from various ural in Twiserkan County, Iran were held.

\section{Participants}

To recruit suitable participants, a purposive sampling method with a maximum variation was used, so that 19 major schools in terms of the number of students and teachers (eight elementary schools, six middle schools and five high schools) of urban and rural areas in the County of Twiserkan were selected. Next, the school health instructor was asked to invite students, parents and school teachers for participating in the study via publishing a message on WhatsApp. For two weeks at the WhatsApp of schools, individuals who were interested in participating in the study were recorded. Proper management was ended with volunteer participants to define the proper place and time for interviewing.

The inclusion criteria were teachers, parents and students at Twiserkan County and endorse an informed consent form to participate in the research. Absence from interviews twice, even after conducting followups via the researchers was exclusion criteria.

\section{Data collection}

Data were collected using a total number of eighty interviews (28 interviews with teacher, 20 with students, and 32 with parents) in Persian language through an interview by two trained data collectors (expert in public health). The first seven interviews helped detect weak and vague points of view of the interview process. Each interview continued for 50-55 min.

After determining demographic characteristics of participants, three structured questions of interviewee about the causes why the concerns and stress about the process of social distancing and reopening schools during the Covid-19 outbreak were asked.

"What do you think about the plan for social distancing and reopening of schools during COVID-19 pandemic?"

"Do you think the plan of social distance and the reopening of schools during COVID-19 pandemic will cause concern and stress?" 
Could you please explain to me more about this issue?" Clearly state your concerns and stress in this regard.

Then, after each interview, the recording of audio was immediately recorded along with their body language such as silence, smiling, crying, and etc. Next, the transcriptions were matched with interview audio tapes. The interviews were performed from April 2020 until May 2020. Sampling continued until the researchers have reached to data saturation. So that in 70th interview was reached to saturation, but 10 additional interviews were performed to confirm consistency in data. To confirm that the similar interview process was performed, the interviews were managed in the existence of both interviewers.

\section{Data analysis}

Diekelmann et al. method was used for data analysis. This method is used in the study of exploratory subjects and that knowledge about it is insufficient [16]. According to this method, in the process of collecting the interviews, the texts of the interviews were rewritten word for word and reviewed several times to obtain a general understanding of it. Then, a commentary summary was written for each of the interview texts and the hidden meanings were understood and extracted. The researchers then participated in the extraction of themes and exchanged views. As the interviews continued, the previous themes became more specific and complete, and sometimes the new themes became clear. To clarify, we categorize and resolve inconsistencies in the interpretation of the process of repeated return to the texts. At each stage, with the integration of interpretive summaries, a more general analysis was performed so that the relationship between the themes was investigated in the best possible way to reach the final design. With categorization based on immersion in information, repetition of coding and classification of information, common and related themes were provided in the form of sub-categories, major themes were combined and finally inappropriate and irrelevant themes were excluded. The participants were contacted again and interviews were conducted as needed to clear up any ambiguity or obtain more information.

\section{Rigor}

Three ways were used for diagnostic accuracy, quality, provide transferability, and reduce the bias in this study. In this study, interviews with different people increased variation in the data in terms of gender, age, job, different areas, and level of education, which improved confirm reliability, ability, and transferability. Data accuracy was confirmed by the researchers' combination throughout the data analysis. Therefore, each interview was independently coded through both of researchers, and the data analysis was matched and discussed between the researchers to attain a discrepancy and consensus. As well as, an expert in the field of qualitative studies controlled all steps of the research.

\section{Results}

The demographic characteristics of the participants were shown in Table 1. 
Table 1

Demographic characteristics of the participants

\begin{tabular}{|c|c|c|c|c|}
\hline \multirow[t]{2}{*}{ Characteristics } & \multirow[t]{2}{*}{ Categories } & \multicolumn{3}{|l|}{$N(\%)$} \\
\hline & & Teacher $(n=28)$ & Student $(n=20)$ & Parent $(n=32)$ \\
\hline \multirow[t]{2}{*}{ Gender } & Male & $12(42.8)$ & $9(45.0)$ & $15(47.0)$ \\
\hline & Female & $16(57.2)$ & $11(55.0)$ & $17(53.0)$ \\
\hline \multirow[t]{6}{*}{ Age group (year) } & $7-12$ & $0(0)$ & $2(10.0)$ & $0(0)$ \\
\hline & $13-18$ & $0(0)$ & $18(90.0)$ & $0(0)$ \\
\hline & $19-29$ & $4(14.3)$ & $0(0)$ & $2(6.2)$ \\
\hline & $29-39$ & $10(35.7)$ & $0(0)$ & 100 \\
\hline & $39-49$ & $6(21.4)$ & $0(0)$ & 180 \\
\hline & Over 50 & $8(28.6)$ & $0(0)$ & $2(6.2)$ \\
\hline \multirow[t]{5}{*}{ Level of education } & No schooling & $0(0)$ & $0(0)$ & $2(6.2)$ \\
\hline & Primary school & $0(0)$ & $2(10.0)$ & $6(17.8)$ \\
\hline & Middle school & $0(0)$ & $8(40.0)$ & $8(25.0)$ \\
\hline & High school \& Diploma & $2(7.2)$ & $10(50.0)$ & $10(31.3)$ \\
\hline & University & $26(92.8)$ & $0(0)$ & $6(18.7)$ \\
\hline \multirow[t]{3}{*}{ Marital status } & Married & $23(82.1)$ & $0(0)$ & $30(93.8)$ \\
\hline & Single & $4(14.3)$ & $20(100)$ & $0(0)$ \\
\hline & Divorced or widowed & $1(3.6)$ & $0(0)$ & $2(6.2)$ \\
\hline \multirow[t]{2}{*}{ Areas } & Urban & $8(28.6)$ & $8(40.0)$ & $13(40.6)$ \\
\hline & Rural & $20(71.4)$ & $12(60.0)$ & 19 (59.4) \\
\hline
\end{tabular}

The data analysis resulted in recognizing 174 primary codes, thirteen categories, and six themes. Themes were as "predisposing factor (knowledge)", "predisposing factor (attitude)", "reinforcing factors", "enabling factors", "epidemiological aspect", and "quality of life". These themes led to the development of a PRECEDE model in this study (Table 2). 
Table 2

Themes, categories and codes, extracted from the study

\begin{tabular}{|c|c|c|}
\hline $\begin{array}{l}\text { Relevant theme derived } \\
\text { from categories }\end{array}$ & Relevant categories & \\
\hline \multirow[t]{2}{*}{$\begin{array}{l}\text { Predisposing factor } \\
\text { (knowledge) }\end{array}$} & $\begin{array}{l}\text { - Cyberspace and } \\
\text { media effect }\end{array}$ & \\
\hline & $\begin{array}{l}\text { - Existence of } \\
\text { previous } \\
\text { experiences }\end{array}$ & \\
\hline \multirow[t]{3}{*}{ Reinforcing factors } & $\begin{array}{l}\text { - Personal } \\
\text { characteristics }\end{array}$ & \\
\hline & - Opinions of others & \\
\hline & $\begin{array}{l}\text { - Policymakers' } \\
\text { decisions }\end{array}$ & \\
\hline \multirow{4}{*}{$\begin{array}{l}\text { Predisposing factor } \\
\text { (attitude) }\end{array}$} & \multirow[t]{2}{*}{ - Personal beliefs } & - Fear of getting sick \\
\hline & & - Obsession \\
\hline & \multirow[t]{2}{*}{ - Religious beliefs } & - Disease prevention and following \\
\hline & & - Religious instructions \\
\hline \multirow[t]{6}{*}{ Enabling factors } & \multirow{3}{*}{$\begin{array}{l}\text { - Trust in the health } \\
\text { care system }\end{array}$} & - Fear of medical errors in diagnosis \\
\hline & & $\begin{array}{l}\text { - Lack of specialists and sufficient equipment in } \\
\text { the country }\end{array}$ \\
\hline & & - Concern about the seriousness of the issue \\
\hline & \multirow{3}{*}{$\begin{array}{l}\text { - Doubts in the } \\
\text { education system }\end{array}$} & - The lack of a system for education \\
\hline & & $\begin{array}{l}\text { - The lack of delivery of protective equipment to } \\
\text { teachers }\end{array}$ \\
\hline & & $\begin{array}{l}\text { - The lack of integrated supervision over the } \\
\text { implementation of protective measures }\end{array}$ \\
\hline \multirow[t]{2}{*}{ Epidemiological aspect } & \multicolumn{2}{|l|}{ - Satisfaction } \\
\hline & \multicolumn{2}{|l|}{ - Acceptance } \\
\hline \multirow[t]{2}{*}{ Quality of life } & \multicolumn{2}{|l|}{$\begin{array}{l}\text { - Fear of lack of } \\
\text { progress }\end{array}$} \\
\hline & \multicolumn{2}{|l|}{ - Feeling of remorse } \\
\hline
\end{tabular}

Theme 1: Predisposing factor (knowledge) 
This theme was extracted from the two classes of cyberspace and media effect and the existence of previous experiences with the process of social distance planning and reopening of schools during Covid19 pandemic.

The effect of cyberspace and media

Most parents, students, and teachers considered the information and the effect they received from the mass media, including television, as one of the most important factors in deciding to implement a social distancing plan. They emphasized that the plan has reduced their stress and concerns about their health, but the thought of reopening schools despite COVID-19 pandemic causes worrying. They also pointed to the role of cyberspace, including Instagram, WhatsApp and Telegram, and the destructive role of these media outlets and the increase in concern in themselves, stating that cyberspace caused the dissemination of misinformation or the issue more or less than its importance.

"In WhatsApp, they say a lot of things that do not fit with reason, for example, the means of transmission that when a person thinks about it, he is afraid to leave his house for a long time and they increase the fear" (a 38-year-old mother).

\section{Previous experiences}

The experiences that individuals have had with other respiratory diseases have been invaluable to them. For example, last winter's flu and the fatality rate of the disease caused teachers, students and their parents worry about the school and its environment. In a way, if a student at school shows signs of the flu, he or she should stay home to reduce the stress of others and the worries of parents and teachers about others' disease. The social distancing plan is a very good plan for the majority of parents and teachers because they will not have the stress of spreading the disease among the students and themselves.

"With the start of the social distancing plan and what I knew from the spread of the virus, I was relieved that nothing more would happen to me, my family, and my children" (a 44-year-old mother).

"Last winter I was all worried that my child would get sick from school and pass it on to us and my other children. I always told him to be careful not to get sick and become close to someone who got a cold" (a 39-year-old father).

\section{Theme 2: Reinforcing factors}

The theme included three categories: personal characteristics, the opinions of others, and the effect of policymakers' decisions.

Personal characteristics

The optimal physical and mental characteristics reduce anxiety and stress about COVID-19 pandemic in individuals. The healthier individuals are, the less likely they are to get sick, and if the schools open, they 
will not have to worry too much. Also, if individuals have good mental health, this will have an increasing effect on physical health and they will experience less anxiety and stress during COVID-19 pandemic and the plan to distance and reopen the school.

"Because my child and I have good physical and mental health, I am not afraid if the schools reopen. I'm not worried because a healthy person will not have a problem" (a 54-year-old father)

Opinions of others

The individuals commented that they were affected by the opinion of others about the social distancing plan. The opinion of others makes them afraid of the outbreak of the disease when the schools reopen and makes them prefer to stay at home to protect their health and that of their families if the schools reopen. The parents are also affected by other family members and other parents, and their stress of reopening schools increases. As the parents all stated, if the schools were opened, they would not allow their children to go to school at all to protect their health and that of their families.

"Our neighbor, whose daughter is my daughter's classmate, told me that she would not send her daughter to school at this time if the schools reopen because I am afraid and I am also very worried and I am sure I will not do this" (a 45-year-old mother).

Policymakers' decisions

After the return of education to normal conditions during COVID-19 pandemic, many individuals, especially teachers who receive their salaries from the government, stated that they were very worried and stressed that they would go back to school and get sick with bad consequences for them. Many teachers stated that because they receive their salaries from the government and are afraid of being fired and reprimanded, they are forced to attend classes after the reopening, which is stressful. Therefore, although they are stressed, they are affected by government decisions due to the situation, and any decision made in the country's corona headquarters should be implemented.

\section{Theme 3: Predisposing factor (attitude)}

The theme included two categories of personal and religious beliefs.

Personal beliefs:

Fear of getting sick and obsession were classified into two subclasses.

Fear of getting sick included individuals feeling stressed and anxious about getting sick when schools reopened. Examples of these are given below.

"I think if the schools open, I will definitely get sick. They say the virus always stays and the risk of transmission is higher in crowded places" (a 33-year-old male teacher). 
"I'm so scared of getting sick that I'm phobic. I'm afraid to die and I'm still very young because of a minor virus. I do not want to go to school at all. Nobody obeys their" (a 15-year-old male student).

Obsession

Obsession with cleanliness and avoiding anything because individuals do not want to get sick was one of the cases they mentioned. Many individuals considered obsession with cleanliness to be their main concern, stating that the school was not clean or timely, and that they were terrified of the school environment for COVID-19 pandemic.

"All these children come to school and they may be infected with the virus, and because the school staff cannot clean and disinfect them every hour, the disease can be transmitted quickly and kill us." "Oh, I am very clean and I got very stressed from going to school because of this disease" (a 44-year-old female teacher).

Religious Beliefs are classified into two subcategories: disease prevention and following religious instructions.

Disease Prevention

Religious beliefs are very important in disease prevention.

"I was a very good person in my life, I had faith and I am not worried about diseases at all. God cares a lot for me and my family, I am not afraid of this disease, and I will send him to school more safely if the schools open" (a 54-year-old mother)

"Our religion prevents us from getting sick from individuals in other communities, and I believe my religion makes us less stressed" (a 38-year-old male teacher)

Following the religious instructions

Following the instructions that the religion of Islam has set for individuals causes them to not have much stress in connection with the reopening of schools. So that following the religious instructions leads to following the protective measures against the spread of COVID-19.

"I feel that following the instructions of Islam causes me to perform behaviors that do not cause diseases and I have no stress" (a 33-year-old female teacher).

\section{Theme 4: Enabling factors}

The given theme was extracted from the two levels of trust in the health care system and doubts in the education system.

Trust in the health care system was classified into three subcategories: fear of medical errors in diagnosis, lack of specialists and sufficient equipment in the country, and concern about the seriousness 
of the issue.

Fear of medical errors in diagnosing the disease

"I think sometimes the physician and the rest of the medical staff can make mistakes and make individuals feel bad because the stress and worry is so much more that my children go to school and get sick and they tell me they're nothing" (a 46-year-old mother)

Lack of specialists and sufficient equipment in the country

"The hospital here has insufficient equipment and if I get sick, no one will give it to me and I will die. For this reason, I do not want the schools to be opened and it is better for this distance plan to continue" (a 33-year-old female teacher)

Concerns about the seriousness of the issue

"I'm worried that Corona is in a very bad condition and if they do not tell us, and I will let my children go to school and get sick" (a 36-year-old father)

The doubts about the education system

The lack of a system for education, delivery of protective equipment to teachers and integrated supervision over the implementation of protective measures was also classified into three sub-categories.

Lack of a system for education

"I am very stressed because in school students are not given consistent and continuous training on how to behave protectively against COVID-19, and it is better to go to school" (a 38-year-old mother)

Failure to deliver protective equipment to teachers

"I'm worried about going to school again because we are not provided with school protective equipment at all and I have to buy it myself" (a 40-year-old female teacher)

Lack of integrated monitoring of the implementation of protective measures

"There is no place in the organization that monitors, protective measures, and recently they say that officials of education and health centers visit and warn schools that do not comply, but I am still worried that this is temporary and does not last" (a 46-year-old male teacher).

\section{Theme 5: Epidemiological aspect}

The theme of the epidemiology aspect of the subject was extracted from the two categories of satisfaction and acceptance.

Satisfaction consisted of two categories: stresses and anxiety. 
Stressful problem

"The issue of distancing and adhering to it, as well as the reopening of schools, is so stressful that I do not want to do anything anymore as if I was helpless" (a 44-year-old female teacher).

Anxiety

"If they say go to school again, I am very stressed under these conditions and I think the reopening of schools is very anxious for me" (a 14-year-old female student).

Acceptance

Acceptance included cases in which individuals were reluctant to think about COVID-19 and stated that it had become a part of our life and we should deal with it.

"I have accepted this disease, which always exists and lives with us. I don't pay much attention anymore. I got tired and told my child that you can go to school" (a 26-year-old mother).

\section{Theme 6: Quality of life}

The theme of quality of life was extracted from two categories: fear of lack of progress and feeling of remorse.

Fear of lack of progress

"With social distance plan and closure of schools, I had no progress in my studies and entrance exam and I am very worried about this" (a 17-year-old female student)

Feeling of remorse

"Ever since this distance plan was implemented and I could not go to school, I have suffered from remorse because I cannot study at home, I hate myself and I am upset" (a 16-year-old male student).

\section{Discussion}

This study was the first study to identify the concerns and stress of parents, students, and teachers about the process of social distance planning and school reopening during Covid-19 Pandemic. Data analysis led to the extraction of 13 sub-themes and 6 main themes including preparing factors, reinforcing factors, preparing factors (attitude), enabling factors, epidemiological aspect of the subject and quality of life, which indicated anxiety and stress in individuals.

The study results showed that there is anxiety and stress in the participants. One of the most stressful situations is the unpredictability of the situation to control the disease and the serious risk of coronavirus. These, along with some misinterpretations and misinformation, can increase anxiety among individuals [17]. On the other hand, challenges and stress can cause disorders such as anxiety and depression [18]. 
Due to this and similar epidemics, in such cases, there are serious concerns such as fear of death among individuals and severe stress and anxiety can occur among individuals who have to stay at home and in the past have been active and educated outside the home [14]. Fear and anxiety due to possible coronavirus infection can be destructive and can lead to psychological disorders and stress in individuals. Fear and stress are beneficial in the short term for the body to deal with stressors [19] but if this fear and stress persist in the long run, it is destructive and leads to a weakened immune system and reduced ability of the body to fight diseases such as coronavirus [20].

The theme of preparing factors (Knowledge) had two categories of the effect of cyberspace and media and the existence of previous experiences in critical situations. The individuals receive a lot of information from different sources and gain experience, process the information obtained and act in different abnormal ways than normal methods. Previous studies have shown that understanding the previous risk and experience have a significant effect of the measures that individuals take when they are at risk $[21,22]$. So that individuals can easily accept the risks or feel less dangerous when the risk is under their control, they can experience and be trained in the management and skills that deal with it. Also, if the risk is simple and a reliable source should raise it and inform about it, and that risk should not be hard and unfamiliar. But if there are limited ways to control the risk, the risk is unknown, the information about it is provided by unreliable sources, it is new and strange, or it affects children, it is less understood, tolerated and experienced, and individuals are very worried [23]. A study results showed that the dissemination of misinformation, including incorrect information, insufficient information, opportunistic misinformation (intentional or unintentional) and sometimes even expired information can be potentially dangerous and threaten public health, and increase anxiety and stress of individuals [24].

The theme of reinforcing factors included three categories of personal characteristics, opinions of others and decisions of policy makers. The majority of participants emphasized that they had good physical and mental health to deal with coronavirus. A study by Rahmatinejad et al. also confirmed that individuals who think they have better physical and mental health experience less anxiety and stress about coronavirus [25]. Also in the implementation of the plan to distance and reopen schools, individuals stated that other important and abstract norms play a key role in their decision-making during Covid-19 Pandemic. This can be explained by the fact that in critical and difficult situations, individuals listen to the opinions of others to make a decision with their help. Most of the participants mentioned that they are affected by the opinions and decisions of policy makers and the government. Therefore, the government should, in addition to exploiting good governance, use all the capacities of the governmental and non-governmental sector, transparency of procedures and information, accountability to community, law enforcement for all, consensus based on popular belief, structural pressure, social motivation and effective strategies to deal with Covid-19 Pandemic with a strategic vision and flexibility in the current situation to create a more general value in social distance, to overcome the crisis of Covid-19 Pandemic [26].

In the present study, the theme of preparing factors (attitude) had two categories: personal and religious beliefs. In the study, the participants noted that the personal beliefs they have in their life make them less 
stressed and anxious. In addition to classical medical treatments, many cultures have organized methods for dealing with physical and mental diseases. In this regard, religious faith and belief have always been important and treatment based on faith in God as a supernatural force has a long history among followers of different religions. As man's insight and belief in religion and belief in divine principles play a decisive role in improving the course of the disease, reducing pain and increasing the tolerance of the complications of the disease, and the use of these potential and valuable forces against diseases is important. So that faith in God and religious belief, calm individuals during difficult and unbearable periods, such as facing diseases [27].

The study results showed that the theme of enabling factors included two categories of trust in the health care system and doubts in the education system. In order to control the crisis in this situation, the government needs coordination, classification and cooperation among different organizations, including organizations involved with individuals' health. For coordination, the medical team should integrate with other resources. For classification, the cooperation of government, social organizations and individuals is needed to defeat coronavirus [26].

The statistics show that with Covid-19 Pandemic, if the relevant organizations are not involved in education and adherence to health protocols, individuals turn to the wrong methods of treatment and not appropriate preventive measures, which in turn leads to death due to lack of knowledge [28].

The theme of the epidemiological aspect of the subject had two categories of satisfaction and acceptance of Covid-19 Pandemic. The participants were concerned with the reopening of schools and the social distancing plan in two ways, either accepting the issue or satisfying with it. So that the result of the previous study showed that individuals who defer may cause problems and stress for other children in the family and their parents [29]. But the individuals who accept the issue and conclude that they should protect their health and that of their family in any situation, take precautionary measures and in any situation show less worry and stress than other individuals in critical situations, including Covid-19 Pandemic.

The theme of quality of life included two categories: fear of lack of progress and feeling of remorse. With the implementation of the social distancing plan and the closure of schools, students and their parents have become more stressed and worried about the educational problems that their children will face due to these holidays, as well as because they cannot do anything special under these conditions they often could not teach their children the lessons and felt remorse. A study results showed that students and parents were afraid of school closure due to Covid-19 Pandemic and their concern in this situation was further increased [30].

It seems that in addition to attempts at various levels to prevent the spread of disease and other worrying conditions, special attention should be paid to the mental health issues of the community, especially those whose educational future is at risk. Providing screening plans for psychiatric disorders, including anxiety and depression in individuals due to the severity of the vulnerability and the lack of available information to understand the current situation and build trust seems essential [14]. 
One of the strengths of this study is that this is the first study in this field. However, one of the limitations of this study is that it does not receive the opinions of planners and policy makers in this regard.

\section{Conclusions}

Identifying and explaining the factors affecting the concerns and stress of parents, students, and teachers about the social distance planning process and the reopening of schools during Covid-19 Pandemic will help policymakers and managers for planning and interventions. The mental health facilities should be considered during Covid-19 Pandemic so that individuals have less stress and anxiety during this period.

\section{Declarations}

\section{Ethics approval and consent to participate}

This study was approved by the Ethical Committee of the Hamadan University of Medical Sciences (reference number: IR.UMSHA.REC.1399.156). The informed consent form, obtaining of participants after informing them of the purpose of the study, rights, potential risks and benefits, procedures to be undertaken, the volunteering of subjects in the study and recording of their voices.

\section{Consent for publication}

Not applicable.

\section{Availability of data and materials}

Not applicable.

\section{Competing interests}

The authors declare that they have no competing interests.

\section{Funding}

This work was supported by Hamadan University of Medical Sciences [reference number: 990223974].

The funder had no role in the design of the study, data collection, analysis, interpretation of the data, writing of the manuscript, or the decision to publish.

\section{Authors' contributions}

We hereby declare that all authors have contributed to this work. SB and MA have written the manuscript. MA, MB, SSMM and JZCT contributed to the calculations and to the writing of the manuscript. SB, MA, and $M B$ have conceived the questionnaires, designed and supervised the study. All authors read and approved the final manuscript. 
Acknowledgements

This project has been approved by the Research and Technology Deputy of Hamadan University of Medical Sciences.

\section{References}

1. Peng PW, Ho PL, Hota SS. Outbreak of a new coronavirus: what anaesthetists should know. BJA: British Journal of Anaesthesia. 2020;124(5):497.

2. Hawryluck L, Gold WL, Robinson S, Pogorski S, Galea S, Styra R. SARS control and psychological effects of quarantine, Toronto, Canada. Emerging Infectious Diseases. 2004;10(7):1206.

3. Nishiura H, Jung S-m, Linton NM, Kinoshita R, Yang Y, Hayashi K, et al. The extent of transmission of novel coronavirus in Wuhan, China, 2020. Multidisciplinary Digital Publishing Institute; 2020;9(2):330.

4. Mahase E. China coronavirus: WHO declares international emergency as death toll exceeds 200 . Bmj. 2020;368:m408.

5. Horton R. Offline: 2019-nCoV-“A desperate plea”. The Lancet. 2020;395(10222):400.

6. Qazi A, Qazi J, Naseer K, Zeeshan M, Hardaker G, Maitama JZ, et al. Analyzing Situational Awareness through Public Opinion to Predict Adoption of Social Distancing Amid Pandemic COVID19. Journal of Medical Virology. 2020.

7. Official website of the President of the Islamic Republic of Iran. Social Distancing Plan in Iran. Retrieved from http://www.president.ir. 2020.

8. Xiang YT, Yang Y, Li W, Zhang L, Zhang Q, Cheung T, et al. Timely mental health care for the 2019 novel coronavirus outbreak is urgently needed. The Lancet Psychiatry. 2020;7(3):228-9.

9. Hall RC, Hall RC, Chapman MJ. The 1995 Kikwit Ebola outbreak: lessons hospitals and physicians can apply to future viral epidemics. General hospital psychiatry. 2008;30(5):446-52.

10. Sim K, Chan YH, Chong PN, Chua HC, Soon SW. Psychosocial and coping responses within the community health care setting towards a national outbreak of an infectious disease. Journal of psychosomatic research. 2010;68(2):195-202.

11. Van Bortel T, Basnayake A, Wurie F, Jambai M, Koroma AS, Muana AT, et al. Psychosocial effects of an Ebola outbreak at individual, community and international levels. Bulletin of the World Health Organization. 2016;94(3):210.

12. Huang C, Wang Y, Li X, Ren L, Zhao J, Hu Y, et al. Clinical features of patients infected with 2019 novel coronavirus in Wuhan, China. The lancet. 2020;395(10223):497-506.

13. Chen N, Zhou M, Dong X, Qu J, Gong F, Han Y, et al. Epidemiological and clinical characteristics of 99 cases of 2019 novel coronavirus pneumonia in Wuhan, China: a descriptive study. The Lancet. 2020;395(10223):507-13. 
14. Lu R, Zhao X, Li J, Niu P, Yang B, Wu H, et al. Genomic characterisation and epidemiology of 2019 novel coronavirus: implications for virus origins and receptor binding. The Lancet. 2020;395(10224):565-74.

15. Rubin GJ, Amlot R, Page L, Wessely S. Public perceptions, anxiety, and behaviour change in relation to the swine flu outbreak: cross sectional telephone survey. Bmj. 2009;339:b2651.

16. Burns N, Grove SK. Understanding nursing research-eBook: Building an evidence-based practice: Elsevier Health Sciences; 2010.

17. Bao Y, Sun Y, Meng S, Shi J, Lu L. 2019-nCoV epidemic: address mental health care to empower society. The Lancet. 2020;395(10224):e37-e8.

18. Dar KA, Iqbal N, Mushtaq A. Intolerance of uncertainty, depression, and anxiety: Examining the indirect and moderating effects of worry. Asian Journal of Psychiatry. 2017;29:129-33.

19. Barrett KE, Barman SM, Brooks HL, Yuan J. Ganong's Review of Medical Physiology. 26th Editon. McGraw-Hill Education: 2019.

20. Yaribeygi H, Panahi Y, Sahraei H, Johnston TP, Sahebkar A. The impact of stress on body function: A review. EXCLI Journal. 2017;16: 1057-72.

21. Rubin GJ, Wessely S. The psychological effects of quarantining a city. Bmj. 2020;368.

22. Seeger MW, Pechta LE, Price SM, Lubell KM, Rose DA, Sapru S, et al. A Conceptual Model for Evaluating Emergency Risk Communication in Public Health. Health security. 2018;16(3):193-203.

23. Gentili D, Bardin A, Ros E, Piovesan C, Ramigni M, Dalmanzio M, et al. Impact of Communication Measures Implemented During a School Tuberculosis Outbreak on Risk Perception among Parents and School Staff, Italy, 2019. International journal of environmental research and public health. 2020;17(3): 911.

24. Zhang J, Shuai L, Yu H, Wang Z, Qiu M, Lu L, et al. Acute stress, behavioural symptoms and mood states among school-age children with attention-deficit/hyperactive disorder during the COVID-19 outbreak. Asian journal of psychiatry. 2020;51:102077.

25. Rahmatinejad P, Yazdi M, Khosravi Z, Shahisadrabadi F. Lived Experience of Patients with Coronavirus (Covid-19): A Phenomenological Study. rph. 2020; 14 (1):70-90.

26. Ghasemi M, Keshtegar A, Mohammadzadeh Z. Good Governance and Public Value Management in the Face of COVID-19. Manage Strat Health Syst. 2020; 5(1):3-6.

27. Ahmadi Abhari SA. The Role of Faith and Religious Beliefs in Healing Physical and Emotional Disorders. IJPCP. 1996; 2(4):1-8.

28. Banerjee D. The COVID-19 Outbreak: Crucial Role the Psychiatrists Can Play. Asian J Psychiatr 2020; 50: 102014.

29. Lee J. Mental health effects of school closures during COVID-19. The Lancet Child \& Adolescent Health. 2020;4(6):42.

30. Prem K, Liu Y, Russell T, Kucharski A, Egoo R,Davis N, et al. The effect of control strategies to reduce social mixing on outcomes of the COVID-19 epidemic in Wuhan, China: a modelling study. Lancet 
Public Health 2020; 5(5): E261-70.

Page 18/18 